Document downloaded from:

http://hdl.handle.net/10251/99175

This paper must be cited as:

Gyftakis, KN.; J. Antonino-Daviu; Garcia-Hernandez, R.; Mcculloch, MD.; Howey, DA.; Marques Cardoso, AJ. (2016). Comparative Experimental Investigation of Broken Bar Fault Detectability in Induction Motors. IEEE Transactions on Industry Applications. 52(2):14521459. doi:10.1109/TIA.2015.2505663

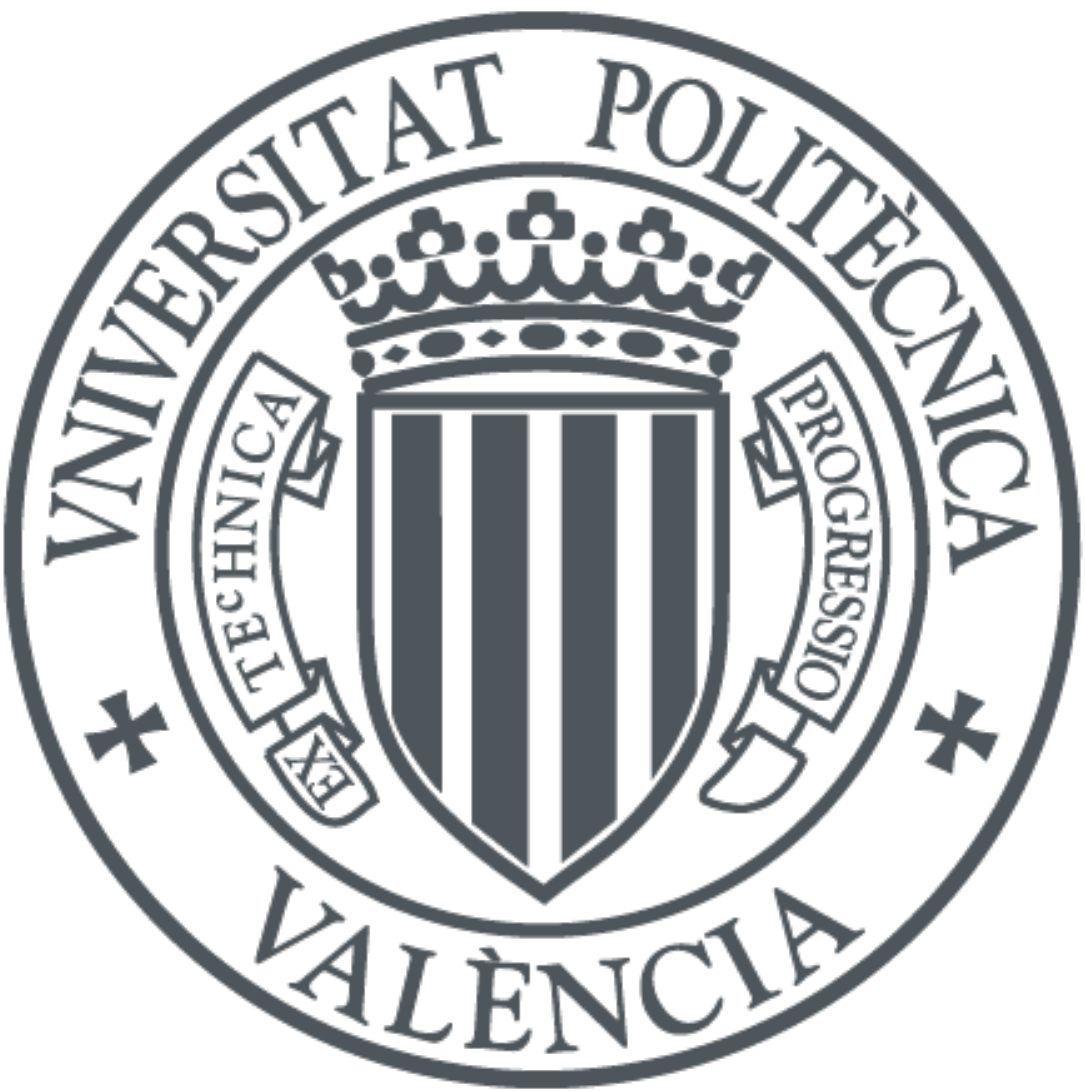

The final publication is available at

https://doi.org/10.1109/TIA.2015.2505663

Copyright Institute of Electrical and Electronics Engineers

Additional Information 


\title{
Comparative Experimental Investigation of Broken Bar Fault Detectability in Induction Motors
}

\author{
Konstantinos N. Gyftakis, Member, IEEE, Jose A. Antonino-Daviu, Senior Member, IEEE, Raul Garcia-Hernandez, \\ Malcolm McCulloch, Senior Member, IEEE, David A. Howey, Member, IEEE and Antonio J. M. Cardoso, Senior \\ Member, IEEE
}

\begin{abstract}
It has been shown in the past that the zerosequence current spectrum can be reliably used to detect broken bar faults in induction motors. Previous work was carried out with extensive FEM analysis. Although it allows detailed study of spatial and time-dependent electromagnetic characteristics of induction motors, FEM is a heavily timeconsuming tool and this limits full study. So, in this work, extensive experimental testing has been performed to validate the zero sequence current spectrum for detecting rotor asymmetries. Three identical induction motors have been used: one healthy, one with a broken rotor bar, and one with two broken rotor bars. The motors were tested under different voltage supply levels and with different mechanical loads. The zero-sequence current spectrum was calculated after measuring the three phase currents. It is for the first time experimentally shown that this approach offers greater diagnostic potential than traditional MCSA.
\end{abstract}

Index Terms - Broken rotor bar, Fault diagnosis, Induction motor, Zero-sequence current.

\section{INTRODUCTION}

$\mathrm{B}$ ROKEN rotor bar faults account for 5-10\% of total induction motor faults [1]-[2]. The mechanisms which lead to this fault are many and are strongly related to the manufacturing process of the motor itself as well as the operating characteristics [3]-[4]. If the induction motor cage is aluminum cast, the broken bar fault is usually the result of air-bubbles inside the bars, created during casting, which lead to hot spots and eventually to local

This work was supported in part by the EPSRC funded FUTURE Vehicles project (EP/I038586/1)

K. N. Gyftakis was with the Energy and Power Group, Dept. of Engineering Science, University of Oxford, Oxford, OX13PJ, UK and currently is with the Coventry University, Priory St, Coventry, UK, CV15FB (e-mail: k.n.gyftakis@ieee.org).

J. A. Antonino-Daviu is with the Institute for Energy Engineering, Universitat Politècnica de València, Camino de Vera s/n, 46022, Valencia, Spain (e-mail: joanda@ die.upv.es).

Raul Garcia-Hernandez is with the Department of Electrical Engineering, Universitat Politècnica de València, Camino de Vera s/n, 46022, Valencia, Spain.

M. McCulloch and D. A. Howey are with the Energy and Power Group, Dept. of Engineering Science, University of Oxford, Oxford, OX13PJ, UK

A. J. M. Cardoso is with the Department of Electromechanical Engineering of the University of Beira Interior, Covilhã, Portugal, and also with CISE - Electromechatronic Systems Research Centre, Covilhã, Portugal (e-mail: ajmcardoso@ieee.org). cracks of the cage [5]. The mechanism of the broken rotor bar fault is usually different in larger industrial induction motors whose cage is fabricated with copper. Thermal expansion of the bars along the shaft direction, vibrations and corrosion are some of the main factors leading to a broken bar fault [6].

Moreover, previous works have shown that, when there is a broken bar fault the neighboring bars are overcharged and are expected in most cases to break subsequently [7]. Despite this, some cases have been reported where the broken bars were not in adjacent positions but in random positions along the rotor circumference influencing negatively the diagnostic reliability of Motor Current Signature Analysis (MCSA) [7]-[10] for this fault.

It is also important to refer to the cases of a false broken bar fault alarm caused by axial cooling air-ducts, a subject that recently has drawn a lot of attention [11]-[13]. Additionally, although the broken bar fault is not usually expected to lead to an abrupt total motor failure, there have been cases where the protrusion of the broken rotor bars caused severe damage to the stator windings leading to significant damage and production shutdowns.

Finite Element Method (FEM) has been used in the past to simulate induction motors under a broken bar fault and offer a deep insight into the magnetic field behavior. In [14] the authors showed that the local saturation has a negative impact on broken bar fault diagnosis. Moreover, in [15] it is shown that a broken bar fault in a 4-pole induction motor caused a parasitic 2-pole magnetic field. Finally, in [16] it was shown that in double cage induction motors the breaking of an upper bar causes the overcharging of the inner bar in the same slot and not the neighboring adjacent bars, clearly showing a different degradation mechanism than in conventional induction motors.

Many methods can be found in the literature dealing with broken rotor bar fault diagnosis [17-18]. Most of the diagnostic techniques used up to now are based on the analysis of the stator current [19]-[21], torque [22]-[23], magnetic flux [24]-[25] and power [26]-[29]. Moreover, different signal processing methods can be found including FFTs [30], time frequency tools [19], [31]-[32], MUSIC [33] etc. It was shown recently [34], with the help of FEM, 
that the Zero-Sequence Current (ZSC) spectrum can be used for the detection and identification of a variety of induction motor faults, including broken rotor bar faults. It was also shown in [35] that the ZSC is less sensitive to the rotor slot number compared to other diagnostic means. Finally, it was shown in [36] with the use of FEM that the ZSC broken rotor bar fault signatures had greater amplitudes than those of the stator current signatures in both single and double cage induction motors.

In this work, the aim is to investigate experimentally the broken rotor bar fault diagnostic ability of the ZSC. For this purpose three identical 3-phase cage induction motors have been tested: one healthy, one with a broken rotor bar and one with two broken rotor bars. The motors were set to operate at rated load, half load and at no load for different voltage supply levels. Their stator windings were connected so that the three phase currents were simultaneously monitored for each specific case, which allows the easy calculation of the ZSC.

The experimental results reveal that the ZSC can be exploited to reliably detect broken rotor bar faults and their severity. Moreover, the ZSC contains much stronger broken rotor bar fault related signatures than the line current spectrum. Finally, the ZSC broken rotor bar diagnostic ability is enhanced by the iron core saturation effect. This can be very useful as a complementary diagnostic tool in industrial motors where access to all phase currents may be easily available.

\section{THEORETICAL ANALYSIS}

Firstly, a theoretical analysis will be presented aiming to properly introduce the reader in the proposed method. It is considered that a 3-phase induction motor (blue) is connected in delta and operates under load (Fig. 1). The yellow sensors are set to monitor the three phase currents namely: $I_{a}, I_{b}, I_{c}$.

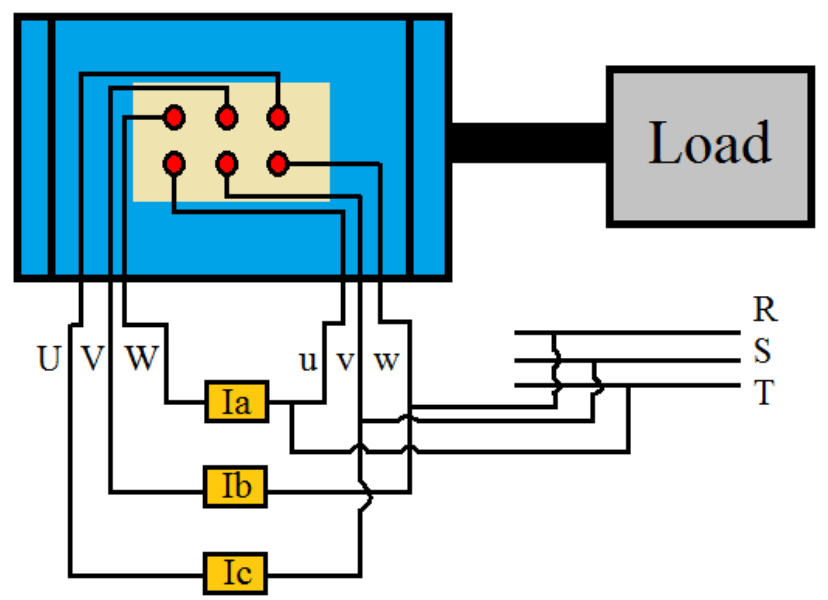

Fig. 1. The delta connected induction motor connected to a load.
The produced first phase-current harmonic constitutes of the following terms:

$I_{a}=I_{M M F_{-} a}+I_{\text {sat_a }}+R S H$

where:

$$
\begin{aligned}
& I_{M M F_{-} a}=\sum_{n=2 k \pm 1}^{\infty} I_{M M F_{-} n} \cos \left(\omega_{n} t\right) \\
& I_{s a t_{-} a}=\sum_{m=2 l \pm 1}^{\infty} I_{M M F_{-} m} \cos \left(\omega_{m} t+\varphi_{\text {sat }}\right)
\end{aligned}
$$

$R S H$ : The Rotor Slot Harmonics, if they exist according to [37].

The three phase currents have 120 degrees phase difference. The zero-sequence current is the sum of the three phase currents and occurs as follows:

$$
\begin{aligned}
I_{Z S C}=3 \sum_{n=3 k}^{\infty} I_{p h_{-} n} \cos \left(\omega_{n} t\right)+ \\
\quad+3 \sum_{m=3 l}^{\infty} I_{\text {sat_m }} \cos \left(\omega_{m} t+\varphi_{\text {sat }}\right)+R S H
\end{aligned}
$$

So, it becomes clear that the fundamental zero-sequence current harmonic is given by:

$$
I_{Z S C_{-} 1}=3\left[I_{p h_{-} 3} \cos \left(3 \omega_{s} t\right)+I_{s a t_{-} 3} \cos \left(3 \omega_{s} t+\varphi_{s a t}\right)\right]
$$

It is clear that the amplitude of the fundamental zerosequence harmonic is saturation level dependant. This means that at no-load operation or low-load operation, the zero-sequence current can reveal the broken bar fault more reliably than traditional MCSA.

If there is a broken bar fault, then fault-related signatures are expected to appear at frequencies:

$f_{b b}=f_{z s c_{-} 1}-2 k s f_{s}, k \in \square$

\section{EXPERIMENTAL TESTING}

\section{A. Test Bench Details}

The test bench as well as the current sensors configuration is shown in Fig. 1. A DC generator was coupled to the motors shaft playing the role of the load. The variable voltage was regulated by means of an autotransformer that was connected at the output of the supply desk. The autotransformer enabled to vary the supply voltage in a wide range (from 0 to the rated voltage of the motor). The three phase currents were monitored for every operating case using current clamps that were connected to a waveform recorder (YOKOGAWA DL-850). The signals were captured at a sampling rate of $5 \mathrm{kHz}$ and the register length was 100 seconds, which gives a good resolution for the FFT analyses. The current signals were initially stored in the recorder and afterwards transferred to a computer. Moreover, the tested induction motor characteristics are shown in Table I. 
TABLE I

INDUCTION MOTOR CHARACTERISTICS

\begin{tabular}{|c|c|}
\hline Rated Power & $1.1 \mathrm{~kW}$ \\
\hline Rated frequency & $50 \mathrm{~Hz}$ \\
\hline Rated Voltage & $230 \mathrm{~V}$ \\
\hline Rated primary current & $4.5 \mathrm{~A}$ \\
\hline Rated speed & $1410 \mathrm{rpm}$ \\
\hline Rated slip & 0.06 \\
\hline Stator windings connection & Delta \\
\hline Number of pole pairs & 2 \\
\hline Number of rotor bars & 28 \\
\hline Number of stator slots & 36 \\
\hline
\end{tabular}

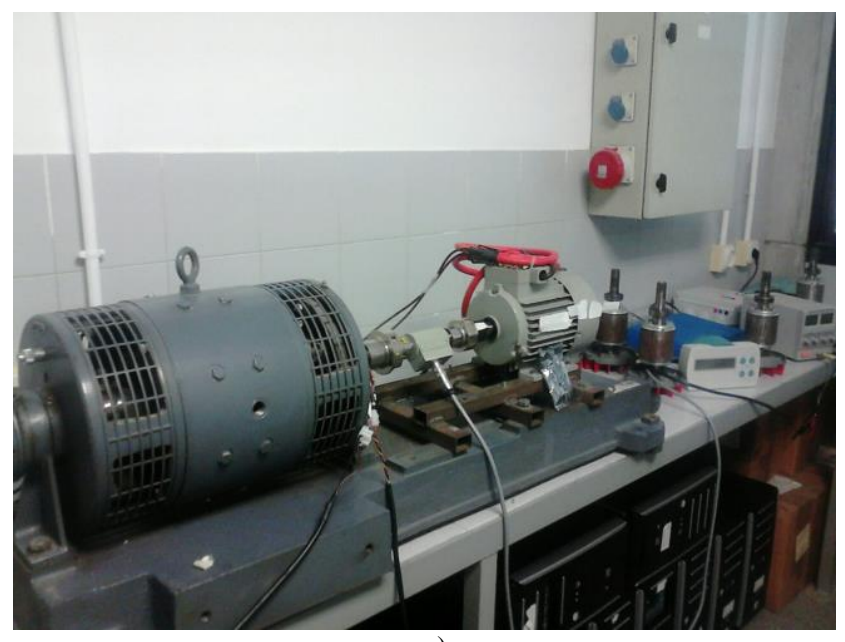

a)

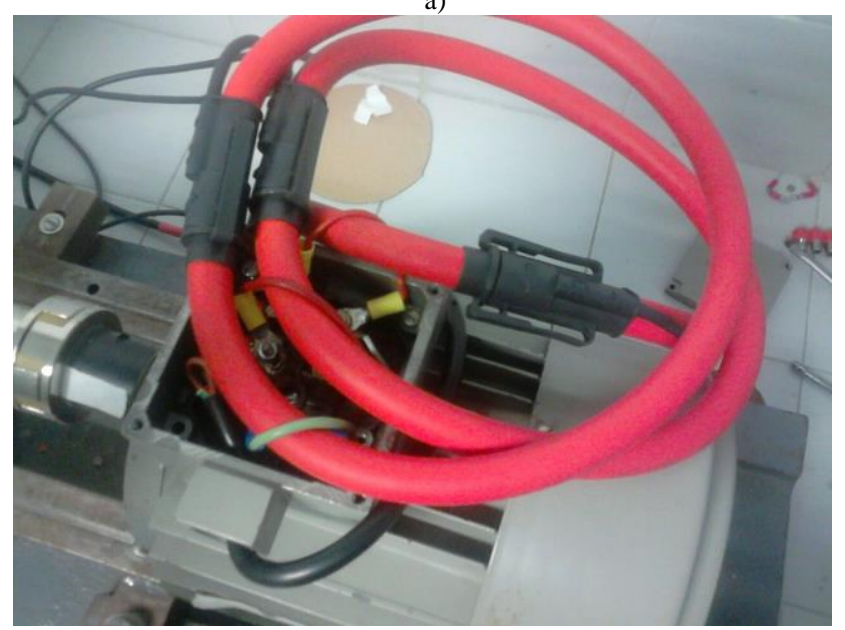

b)

Fig. 1. The test bench where it is shown: a) the coupling between induction motor and load and $b$ ) the current sensors configuration.

\section{B. MCSA Results}

It is well established that broken bar faults produce a specific signature in the line current spectrum, located at frequency $f_{s}-2 s f_{s}$ (left sideband component). Due to speed oscillations [17], there will be a right sideband harmonic too, located at $f_{s}+2 s f_{s}$. This procedure will end by the production of harmonics located at $f_{s} \pm 2 s f_{s}$. Similarly, previous contributions have shown that broken bar fault signatures close to the fifth and seventh current harmonics offer valuable broken bar fault detection potential [30], [38]. Therefore, before analyzing the ZSC results, it is crucial to study the MCSA method's capability in detail.

In Fig. 2 and Fig. 3, the frequency spectra close to the fundamental line current and the fifth harmonic are presented respectively for all tested motors at rated conditions. For a better overview, the amplitudes of the various broken bar fault signatures are illustrated in Table II. The results are consistent with previously published contributions.

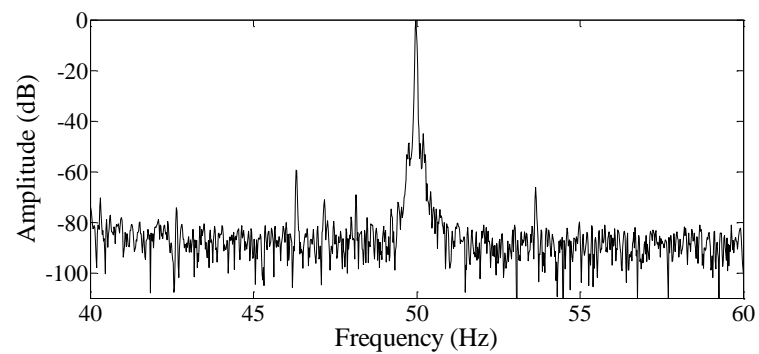

a)
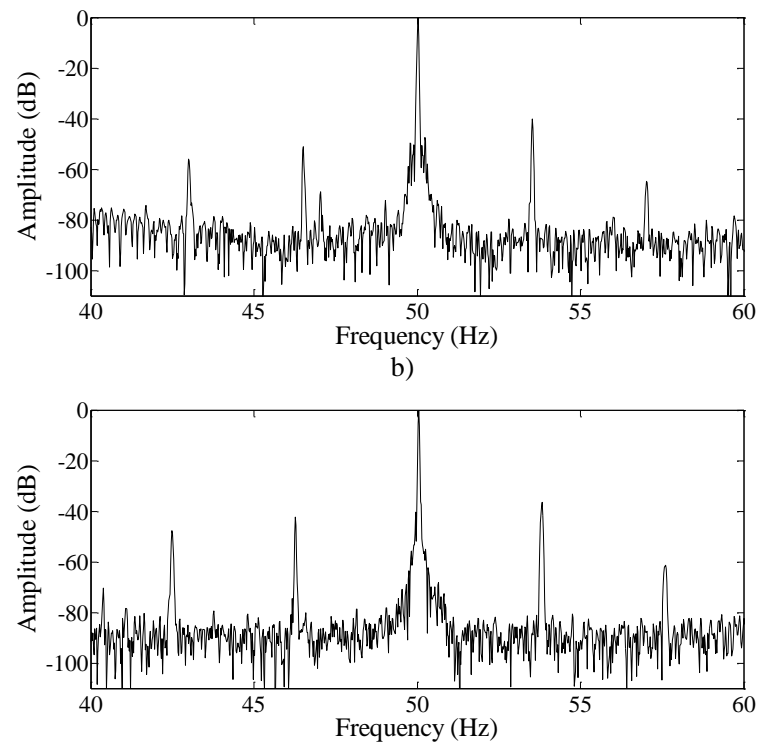

Fig. 2. Frequency spectra around the fundamental line current harmonic for: a) healthy, b) motor with 1 broken bar and c) motor with 2 broken bars.

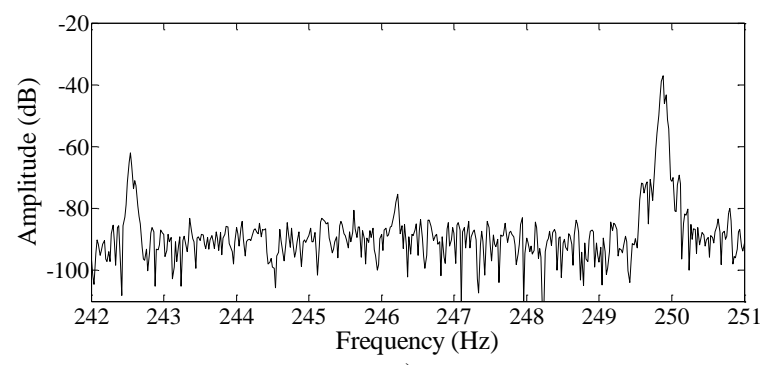




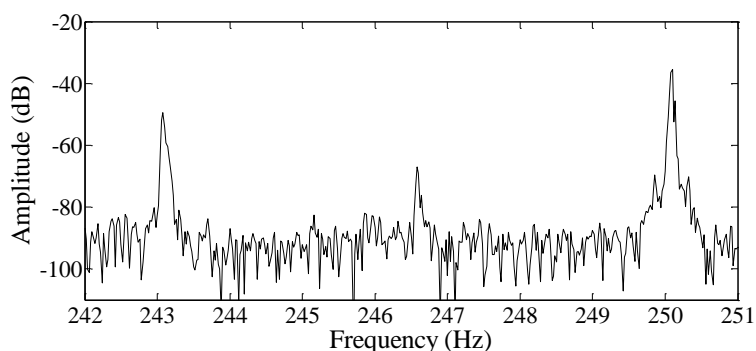

b)

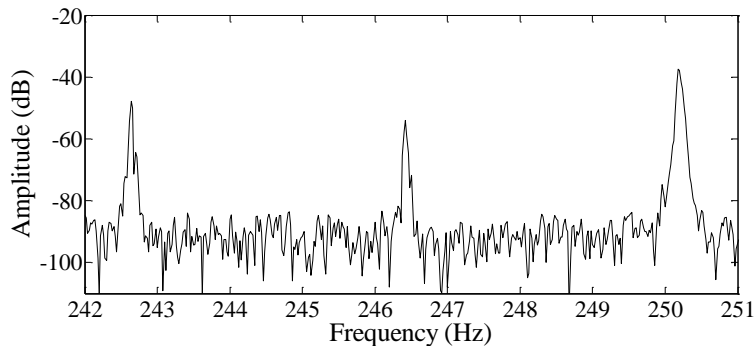

c)

Fig. 3. Frequency spectra around the fifth line current harmonic for: a) healthy, b) motor with 1 broken bar and c) motor with 2 broken bars.

TABLE II

LiNE CURRENT BROKEN BAR FAULT SignATURES

\begin{tabular}{|c|c|c|c|}
\cline { 2 - 4 } \multicolumn{1}{c|}{} & Healthy & 1 broken bar & 2 broken bars \\
\hline fs-4sfs & -74.29 & -56 & -47.58 \\
\hline fs-2sfs & -59.29 & -51.05 & -42.22 \\
\hline fs+2sfs & -66.19 & -40.04 & -36.56 \\
\hline fs+4sfs & -88.13 & -65.16 & -61.45 \\
\hline 5fs-4sfs & -61.99 & -49.42 & -47.8 \\
\hline 5fs-2sfs & -75.38 & -66.94 & -53.94 \\
\hline
\end{tabular}

\section{ZSC Results}

In this subsection, the results from the application of the ZSC methodology will be shown and its diagnostic ability will be evaluated. In Fig. 4 the ZSC frequency spectrum close to its fundamental frequency $f_{Z S C}=3 f_{s}$ is presented.

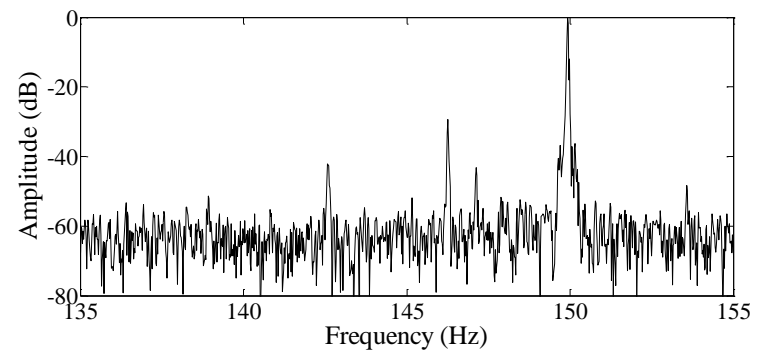

a)

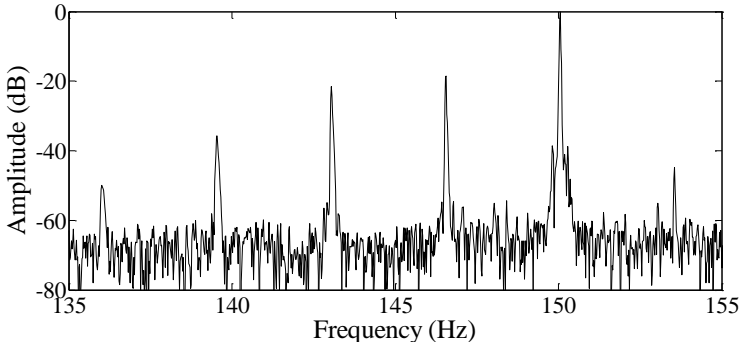

b)

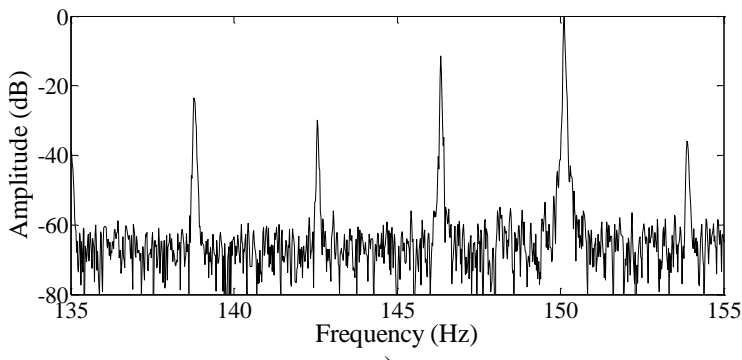

c)

Fig. 4. Frequency spectra around the fundamental ZSC harmonic for: a) healthy, b) motor with 1 broken bar and c) motor with 2 broken bars when the motors operate at rated load.

The amplitudes of the various signatures indicating the broken bar fault are shown in Table III. It is clear that the broken bar fault signatures are characterized by significant amplitudes, which can be more than $20 \mathrm{~dB}$ greater than those located close to the fundamental component of the line current (Table II).

It can be seen that the healthy motor has a significant signature at $3 f_{s}-2 s f_{s}$. That signature is well known to be produced by shaft oscillations. The amplitude of this specific harmonic increases by about $9 \mathrm{~dB}$ and $18 \mathrm{~dB}$ for the motors with 1 and 2 broken rotor bars, respectively. Despite that, it is logical to assume that this harmonic could lead to a false positive alarm by a diagnostics engineer. Alternatively, the $3 f_{s}-4 s f_{s}$ and $3 f_{s}-6 s f_{s}$ harmonics increase only under the broken rotor bar fault existence. The $3 \mathrm{fs}-6 \mathrm{sfs}$ seems to be most influenced by the fault and presents the greater amplitude. Moreover, this signature is clearly fault severity sensitive.

TABLE III

\begin{tabular}{|c|c|c|c|}
\multicolumn{1}{c|}{} & \multicolumn{2}{c|}{ ZSC BROKEN BAR FAULT SIGNATURES } \\
\cline { 2 - 4 } \multicolumn{1}{c|}{} & Healthy & 1 broken bar & 2 broken bars \\
\hline 3fs-6sfs & -51.37 & -35.68 & -23.57 \\
\hline 3fs-4sfs & -42.22 & -21.57 & -29.82 \\
\hline 3fs-2sfs & -29.43 & -18.59 & -11.4 \\
\hline 3fs+2sfs & -48.38 & -44.87 & -35.94 \\
\hline
\end{tabular}




\section{Investigation at No-load Operation}

A known disadvantage of traditional MCSA is that it is unreliable at no-load or low load operation of induction motors because a broken rotor bar fault signature frequency is slip dependent, and when slip is close to zero, this harmonic is usually hidden by the stronger fundamental component. Therefore it is important to evaluate and compare the ZSC and line current broken rotor bar fault detection abilities at no-load.

Fig. 5 illustrates the line current frequency spectra of all three motors in the area close to the fundamental component. It is clear that the left sideband harmonic is unreliable for detection because due to load oscillations it is also present in the healthy case. However, the diagnosis is possible using the right sideband signature.

Additionally, it is shown in Fig. 6 that, the frequency band close to $f_{Z S C}=3 f_{s}$ offers reliable diagnostic potential through the existence of a zone of harmonics related to the fault.

The amplitudes of the broken bar fault signatures are summarized in Table IV for a better overview. Not only do the ZSC signatures have significantly greater amplitudes than the line current but also they offer better severity estimation information. This is evident from the fact that for the MCSA case the broken bar fault signatures in the motors with 1 and 2 broken bars have 2-3 dB amplitude difference. Instead, the $3 f_{s}-6 s f_{s}$ signature of the ZSC spectrum increases by about $5 \mathrm{~dB}$ between the motors with 1 and 2 broken rotor bars respectively.

It is important to note that the motors used for this investigation are small. In larger motors, the no-load speed is much closer to the synchronous speed and thus making the identification of broken bar faults unreliable through the use of the line current spectrum. Instead, it is to be expected that the zone of broken bar fault harmonics offered by the ZSC will be able to reveal the fault, but this is yet to be tested experimentally in large motors.

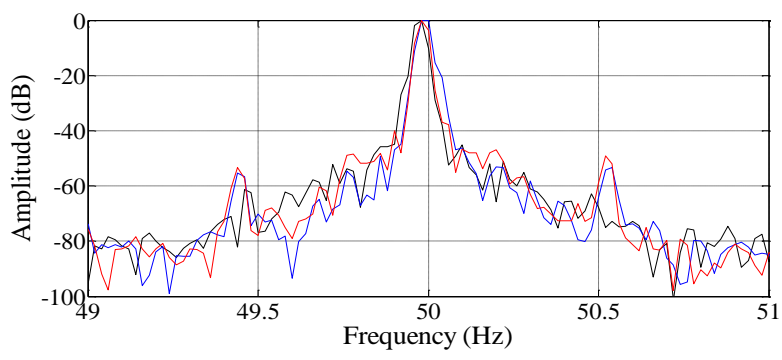

Fig. 5. The frequency spectrum of: healthy (black), motor with one broken bar (blue) and motor with two broken bars (red) at no load.
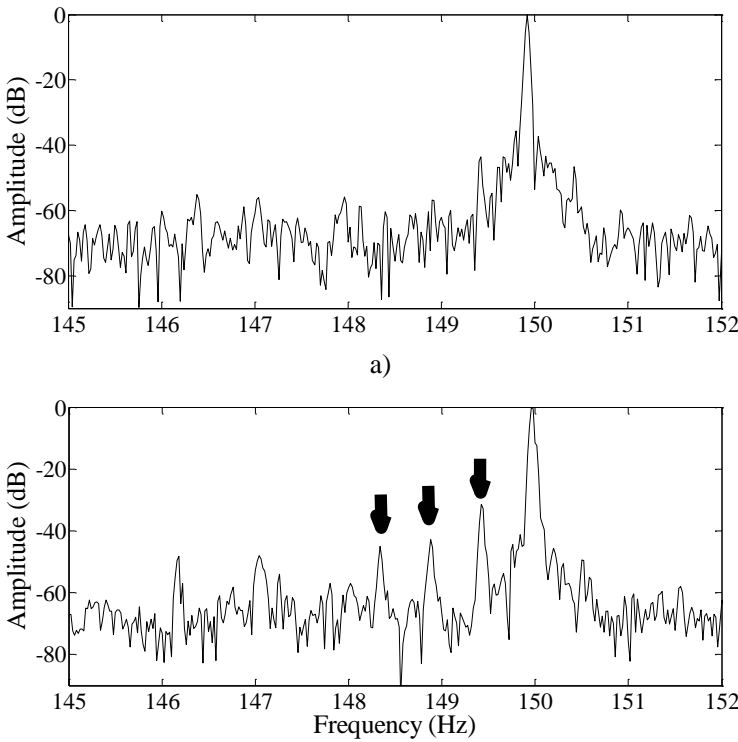

b)

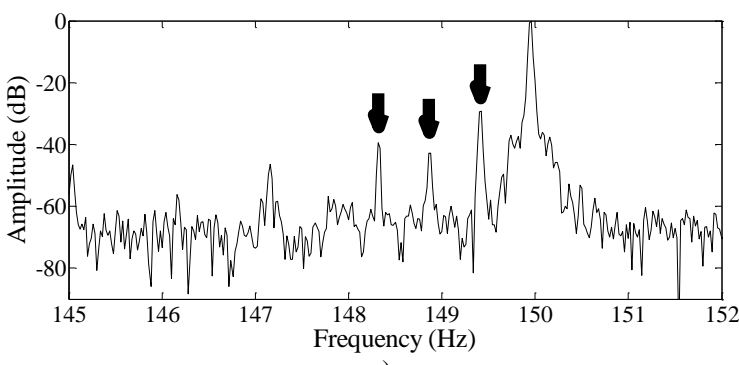

c)

Fig. 6. Frequency spectra around the fundamental ZSC harmonic for: a) healthy, b) motor with 1 broken bar and c) motor with 2 broken bars when the motors operate at no load.

TABLE IV

BROKEN BAR FAULT SigNATURES AT NO LOAD

\begin{tabular}{|l|c|c|c|}
\cline { 2 - 4 } \multicolumn{1}{c|}{} & Healthy & 1 broken bar & 2 broken bars \\
\hline $\begin{array}{l}\text { MCSA } \\
\text { fs-2sfs }\end{array}$ & -61.24 & -55.4 & -53.27 \\
\hline $\begin{array}{l}\text { MCSA } \\
\text { fs+2sfs }\end{array}$ & -62.8 & -52 & -49.09 \\
\hline $\begin{array}{l}\text { ZSC } \\
\text { 3fs-6sfs }\end{array}$ & -60.36 & -44.92 & -39.51 \\
\hline $\begin{array}{l}\text { ZSC } \\
\text { 3fs-4sfs }\end{array}$ & -56.91 & -42.71 & -42.85 \\
\hline $\begin{array}{l}\text { ZSC } \\
\text { 3fs-2sfs }\end{array}$ & -43.59 & -31.36 & -29.29 \\
\hline
\end{tabular}

\section{E. ZSC Signature Behaviour with Voltage Supply Level}

In this subsection, the impact of voltage supply and load level on the broken rotor bar fault signatures of the ZSC spectrum will be shown. For this purpose, measurements at three different load levels: nominal, half nominal and noload were conducted. For each load level, different voltage levels were studied. After analysis, the amplitudes of the $3 f_{s}-2 s f_{s}$ broken bar fault signatures were extracted from all cases and plotted (Fig. 7). 
It can be seen that for nominal load and half nominal load the proposed ZSC signature is fault severity sensitive for every voltage supply level. Similar is the behaviour at no-load operation except some small variation of the signatures amplitude in the healthy motor. This was caused by a random shaft oscillation, which if it happens at no-load, it can significantly influence the current harmonic index due to the rotor irregular movement.

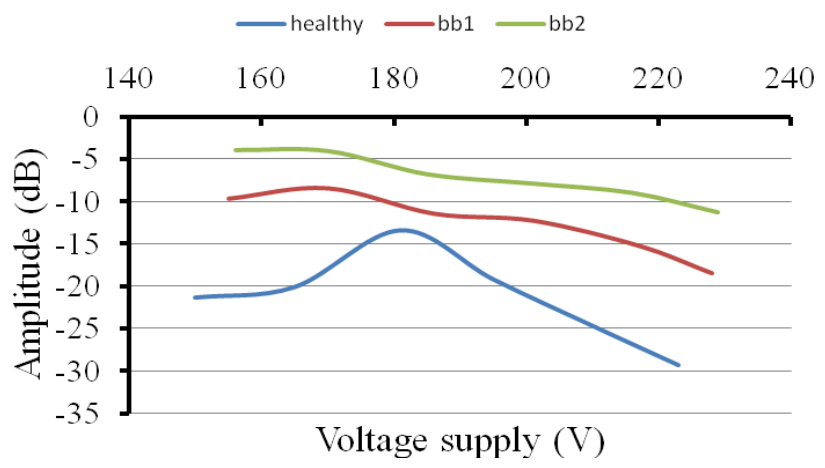

a)

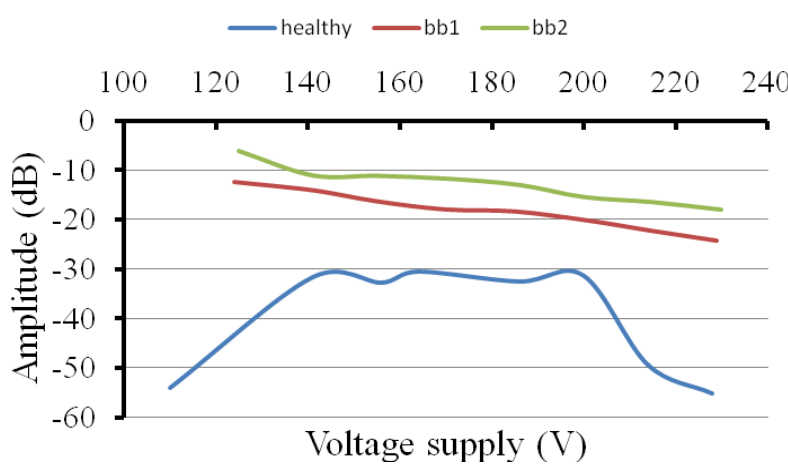

b)

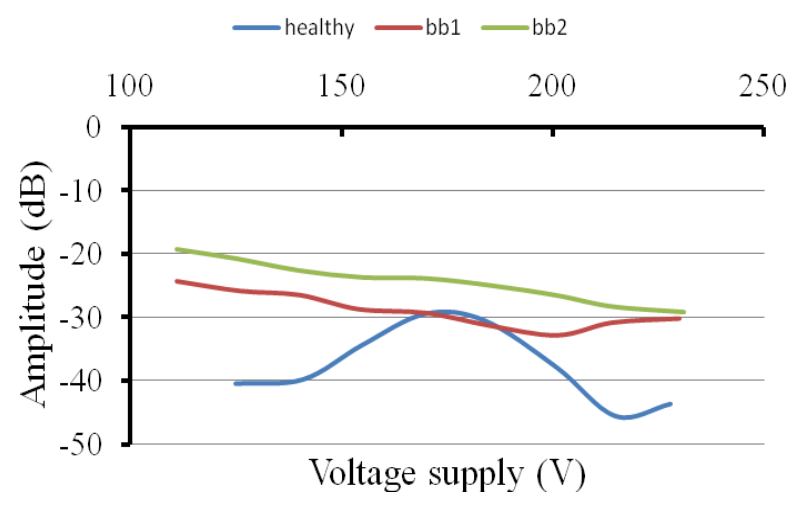

c)

Fig. 7. The amplitude of the $3 \mathrm{fs}-2 \mathrm{sfs}$ broken bar fault signature versus the voltage supply level for: a) nominal load, b) half nominal load and c) no load operation.

\section{MCSA VS ZSC}

In this section, the two methods, MCSA and ZSC, will be discussed and compared, taking into consideration the outcomes of this work.

The obvious advantages of MCSA are the following:

$>$ Only one current sensor is needed,

$>$ Application is independent from the stator winding configuration,

$>$ The approach is simple,

$>$ It can be applied in already installed induction motors at any time.

Instead, ZSC requires three current sensors and can only be applied in delta connected stator windings or star connected with the neutral connected. For those reasons it is not as simple as MCSA. Moreover, the ZSC is the sum of the three phase currents which means that it is not possible in the case of a delta connected motor to have access to the winding as long as the motor operates. In such a case the monitoring equipment could be installed after scheduled maintenance where a motor would be disconnected from the grid.

On the other hand, the ZSC has a variety of advantages which make it a competitor to MCSA:

$>$ It offers much stronger broken rotor bar fault signatures compared to those of MCSA. More importantly, the signatures have comparable amplitudes with the ZSC fundamental component. So, the accuracy of the measurement is significantly improved.

$>$ Due to the higher frequency of the ZSC fundamental component ( $3 \mathrm{fs}$ ) compared to that of MCSA (fs), the rotor is influenced by a stronger skin effect and thus the flux does not penetrate deep in the rotor core. As a consequence, broken bar fault information is stronger in the ZSC and that is why even the $3 f_{s}-6 s f_{s}$ harmonic offers good diagnostic potential that is independent from shaft oscillations.

$>$ It has been shown in the past that the saturation effect decreases the diagnostic potential of MCSA [14]. However, the ZSC is saturation related and thus the saturation level increase has a positive impact on broken rotor bar fault identification.

$>$ The ZSC offers better diagnostic capabilities at no-load operation. Moreover, it is obvious that it is less speed sensitive than MCSA and that is because of the zone where broken rotor bar fault harmonics are produced. If the slip is very close to zero, the $f_{s} \pm 2 s f_{s}$ components of the line current will not be observable. Probably the same will happen with the $3 f_{s}-2 s f_{s}$ ZSC components. But still there will be the $3 \mathrm{fs}-4 \mathrm{sfs}$ and $3 f_{s}-6 s f_{s}$ which can be used for diagnosis. 
$>$ As it can be seen from Fig. 7 the ZSC is a diagnostic tool that is sensitive to the severity of the fault. Voltage supply level can influence the diagnosis for no load operation as it can be seen in Fig. 7-c but diagnosis at operation under load is reliable.

$>$ Also, previous works have shown that the ZSC can reveal static eccentricity faults in PSHinduction motors [34], as well as supply imbalances, so it contains much more valuable information for induction motor condition monitoring compared to MCSA.

$>$ Finally, the proposed method has some common advantages with the monitoring of the broken rotor bar fault close to higher frequencies $\left(5^{\text {th }} / 7^{\text {th }}\right)$ of the line current (deeper flux penetration, slip independency). However, this paper's proposed method has a distinct advantage over those methods; the increased measurement accuracy. That is because although the amplitudes of the fault signatures $5^{\text {th }}$ and $7^{\text {th }}$ harmonics sidebands are important compared to the amplitudes of the $5^{\text {th }}$ and $7^{\text {th }}$ harmonics themselves, however they are still low compared to the amplitude of the fundamental current harmonic. This does not happen with the ZSC case.

\section{CONCLUSIONS}

In this paper, the broken rotor bar fault diagnosis through the use of the zero-sequence current spectrum is evaluated. Three motors have been tested: a healthy, one with a broken rotor bar and another with two adjacent broken rotor bars. The results indicate that the ZSC offers much greater diagnostic signatures than the traditional MCSA. Moreover, the diagnosis is more reliable at no-load operation as the ZSC is less speed sensitive than the MCSA. Finally, extensive testing for different voltage levels and for three different load levels has shown that the ZSC broken bar fault signature is fault severity sensitive. Future works should concentrate on testing larger motors with speed very close to the synchronous one, double cage induction motors, as well as the impact of non-adjacent broken bars on the ZSC diagnostics ability.

\section{REFERENCES}

[1] M. Haji and H. A. Toliyat, "Pattern Recognition-A Technique for Induction Machines Rotor Broken Bar Detection," IEEE Trans. Ener. Conv., Vol. 16, No. 4, pp. 312-317, Dec. 2001.

[2] B. Ayhan, C. Mo-Yuen and S. Myung-Hyun, "Multiple Discriminant Analysis and Neural-Network-Based Monolith and Partition FaultDetection Schemes for Broken Rotor Bar in Induction Motors," IEEE Trans. Ind. Elec., Vol. 53, No. 4, pp. 1298-1308, Jun. 2006.

[3] S. Nandi, H. Toliyat, and X. Li, "Condition monitoring and fault diagnosis of electrical motors-a review," IEEE Trans. Ener. Conv., Vol. 20, No. 4, pp. 719-729, Dec. 2005.

[4] P. Zhang, Y. Du, T. G. Habetler, and B. Lu, "A survey of condition monitoring and protection methods for medium-voltage induction motors," IEEE Trans. Ind. Appl., Vol. 47, No. 1, pp. 34-46, Jan./Feb. 2011.

[5] D. G. Dorrell, L. Frosini, G. Galbiati, and M.-F. Hsieh, "Analysis of axial voltages and inter-bar currents in cast copper cage rotors during DC current injection as an aid to identify casting faults," in Proc. IEEE 35th Annu. Conf. Ind. Electr., Nov. 3-5, 2009.

[6] G. C. Stone, M. Sasic, D. Dunn and I. Culbert, "Recent problems experienced with motor and generator windings," IAS $56^{\text {th }}$ Annual Petroleum and Chemical Industry Conference, pp. 1-9, Anaheim, CA, 2009.

[7] G. Y. Sizov, A. Sayed-Ahmed, C. C. Yeh and Nabeel A. O. Demerdash, "Analysis and Diagnostics of Adjacent and Nonadjacent Broken-Rotor-Bar Faults in Squirrel-Cage Induction Machines," IEEE Trans. Ind. Elec., Vol. 56, No. 11, pp. 4627-4641, Nov. 2009.

[8] C. Hargis, B. G. Gaydon, K. Kamash, "The detection of rotor defects in induction motors," Proceedings of the 1982 IEE Int. Conf. Elec. Mach., London, UK, pp. 216-220, 1982.

[9] T. J. Sobczyk, W. Maciolek, "Does the component (1-2s)f0 in stator current is sufficient for detection of rotor cage faults?", Proc. SDEMPED 2005, Vienna, Austria, pp. 1-5, Sep. 2005.

[10] M. Riera-Guasp, J. Pons-Llinares, F. Vedreno-Santos, J. A. AntoninoDaviu and M. Fernandez Cabanas, "Evaluation of the amplitudes of high-order fault related components in double bar faults," Proc. SDEMPED 2011, Bologna, Italy, pp. 307-315, Sep. 2011.

[11] C. Yang, T. Kang, D. Hyun, S. B. Lee, J. A. Antonino-Daviu, J. PonsLlinares, "Reliable Detection of Induction Motor Rotor Faults Under the Rotor Axial Air Duct Influence," IEEE Trans. Ind. Appl., Vol. 50, No. 4, pp. 2493-2502, Jul 2014.

[12] J. A. Antonino-Daviu, S. B. Lee and E. Wiedenbrug, "Reliable detection of rotor bar failures in induction motors operating in petrochemical plants," Proc. PCIC Europe, Amsterdam, Netherlands, pp. 1-9, Jun. 2014.

[13] S. Lee, J. Hong, S. B. Lee, E. Wiedenbrug, M. Teska and H. Kim, "Evaluation of the influence of rotor axial air ducts on condition monitoring of induction motors," 2012 IEEE ECCE, pp. 3016-3023, Raleigh, NC, Sep. 2012.

[14] J. Sprooten and J.-C. Maun, "Influence of saturation level on the effect of broken bars in induction motors using fundamental electromagnetic laws and finite element simulations," IEEE Trans. Ener. Conv., vol. 24, no. 3, pp. 557-564, Sep. 2009.

[15] A. Belahcen, J. Martinez and T. Vaimann, "Comprehensive computations of the response of faulty cage induction machines," 2014 Int. Conf. Elec. Mach., ICEM, pp. 1510-1515, Berlin, Germany, Sep. 2014.

[16] K. N. Gyftakis, D. K. Athanasopoulos and J. C. Kappatou, "Evaluation of different broken-bar fault diagnostic means in doublecage induction motors with FEM," IEEE SDEMPED 2013, Valencia, Spain, Aug. 2013.

[17] M. Riera-Guasp, J.A. Antonino-Daviu, G.-A. Capolino, "Advances in Electrical Machine, Power Electronic, and Drive Condition Monitoring and Fault Detection: State of the Art," IEEE Transactions on Industrial Electronics, vol.62, no.3, pp.1746-1759, March 2015

[18] H. Henao, G-A. Capolino, M. Fernández-Cabanas, F. Filippetti, C. Bruzzese, E. Strangas, R. Pusca, J. Estima, M. Riera-Guasp, and S.H. Kia, "Trends in Fault Diagnosis for Electrical Machines," IEEE Industrial Electronics Magazine, June 2014, pp. 31-42.

[19] S.H. Kia, H. Henao, G.-A. Capolino, "Diagnosis of Broken-Bar Fault in Induction Machines Using Discrete Wavelet Transform Without Slip Estimation," in IEEE Transactions on Industry Applications, vol.45, no.4, pp.1395-1404, July-aug. 2009.

[20] F. Filippetti, G. Franceschini, C. Tassoni, and P. Vas, "AI techniques in induction machines diagnosis including the speed ripple effect," IEEE Trans. Ind. Appl., vol. 34, no. 1, pp. 98-108, Jan./Feb. 1998.

[21] J. Milimonfared, H. M. Kelk, S. Nandi, A. D. Minassians, and H. A.Toliyat, "A Novel approach for broken-rotor-bar detection in cage induction motors," IEEE Trans. Ind. Appl., Vol.35, pp.1000-1006, Sep./Oct. 1999.

[22] S. J. Manolas and J. A. Tegopoulos, "Analysis of squirrel cage induction motors with broken bars and rings," IEEE Trans. Ener. Conv., Vol.14, No. 4, pp. 1300-1305, Dec. 1999.

[23] M. Eltabach, A. Charara, I. Zein, and M. Sidahmed, "Detection of broken rotor bar of induction motors by spectral analysis of the 
electromagnetic torque using luenberger observer," in Proc. IEEE 27th Annu. Conf. Ind. Eletron. Soc., Denver, CO, USA, Nov. 29Dec. 02 2001, pp. 658-663.

[24] A. Yasidi, H. Henao and G. A. Capolino, "Broken rotor bars fault detection in squirrel cage induction motors," 2005 IEMDC, pp. 741747, San Antonio, TX, May 2005.

[25] K. Bacha, M. Gossa, H. Henao and G. A. Capolino, "Comparative Investigation of Diagnosis Media of Stator Voltage Asymmetry and Rotor Broken Bars in Induction Machines," $32^{\text {nd }}$ IECON, pp. 50405045, Paris, France, Nov. 2006.

[26] Z. Liu, X. Yin, Z. Zhang, D. Chen, and W. Chen, "Online rotor mixed fault diagnosis way based on spectrum analysis of instantaneous power in squirrel cage induction motors," IEEE Trans. Ener. Conv., vol. 19 , no. 3 , pp. $485-490$, Sep. 2004.

[27] M. Eltabach, A. Charara, and I. Zein, "A comparison of external and internalmethodsofsignalspectralanalysisforbrokenrotorbarsdetection in induction motors," IEEE Trans. Ind. Elect., vol. 51, no. 1, pp. 107121, Feb. 2004.

[28] M. Drif and A. J. M. Cardoso, "Noninvasive Rotor Cage Fault Diagnostics in Three-Phase Induction Motors Using the $\alpha, \beta$ Instantaneous Active Power Approach", International Journal of Comadem, Vol.10, No3, pp. 19-28, July, 2007.

[29] M. Drif and A. J. M. Cardoso, "The Use of the InstantaneousReactive-Power Signature Analysis for Rotor-Cage-Fault Diagnostics in Three-Phase Induction Motors", IEEE Trans. Ind. Elect., Vol. 56, No. 11, pp. 4606-4614, November, 2009

[30] H. Henao, H. Razik, and G.-A. Capolino, "Analytical approach of the stator current frequency harmonics computation for detection of induction machine rotor faults," IEEE Trans. Ind. Appl., Vol. 41, No.3, pp. 801-807, May/Jun. 2005.

[31] I. P. Tsoumas, G. Georgoulas, E. D. Mitronikas and A. N. Safacas, "Asynchronous Machine Rotor Fault Diagnosis Technique Using Complex Wavelets," IEEE Trans. Ener. Conv., Vol. 23, No. 2, pp. 444-459, Jun. 2008.

[32] K. Yahia, A. J. M. Cardoso, A. Ghoggal and S. E. Zouzou, "Induction Motors Broken Rotor Bars Diagnosis Through the Discrete Wavelet Transform of the Instantaneous Reactive Power Signal under Time-Varying Load Conditions", Electric Power Components and Systems, Vol. 42, No. 7, pp. 682-692, April, 2014.

[33] A. Garcia-Perez, R. J. Romero-Troncoso, E. Cabal-Yepez et al, "Startup current analysis of incipient broken bar in induction motors using high-resolution spectral analysis," Proc. SDEMPED, pp. 657663, Bologna, Italy, Sep. 2011.

[34] K. N. Gyftakis and J. C. Kappatou, "The zero-sequence current as a generalized diagnostic mean in $\Delta$-connected three-phase induction motors," IEEE Trans. Ener. Conv., Vol. 29, No. 1, pp. 138-148, Mar. 2014.

[35] K. N. Gyftakis and J. C. Kappatou, "Evaluation of the broken bar fault detectability depending on the rotor bar number," $39^{\text {th }}$ IECON, Vienna, Austria, pp. 2798-2803, Nov. 2013.

[36] K. N. Gyftakis, D. K. Athanasopoulos and J. C. Kappatou, "Broken bar fault diagnosis in single and double cage induction motors fed by asymmetrical voltage supply," $9^{\text {th }}$ SDEMPED, Valencia, Spain, pp. 402-406, Sep. 2013

[37] G. M. Joksimovic, J. Riger, T. M. Wolbank, N. Peric, M. Vasak, "Stator-Current Spectrum Signature of Healthy Cage Rotor Induction Machines ,"IEEE Trans. Ind. Elec., Vol. 60, No. 9, pp. 4025-4033, Sept. 2013.

[38] T. J. Sobczyk and Waclaw Maciolek, "Diagnostics of Rotor-Cage Faults Supported by Effects due to Higher MMF Harmonics," IEEE Powertech Conference, Bologna, Italy, 23-26 June 2003.

\section{AUTHORS' INFORMATION}

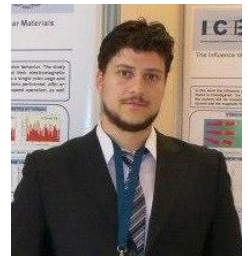

Konstantinos N. Gyftakis (M'11) was born in Patras, Greece, in May 1984. He received the Diploma in Electrical and Computer Engineering from the University of Patras, Patras, Greece in 2010. He pursued a Ph.D in the same institution in the area of electrical machines condition monitoring and fault diagnosis. Then he worked as a PostDoctoral Research Assistant in the Dept. of
Engineering Science, University of Oxford, UK. He is currently a Lecturer Faculty of Engineering, Environment and Computing, Coventry University, UK. His research activities are in fault diagnosis, condition monitoring and degradation of electrical machines. He has authored/co-authored more than 30 papers in international scientific journals and conferences. (E-mail: k.n.gyftakis@ieee.org).

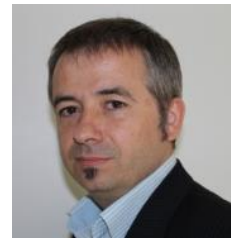

Jose Antonino-Daviu (S'04/M'08/SM'12) received his M.S. and Ph. D. degrees in Electrica Engineering, both from the Universitat Politècnica de València, in 2000 and 2006, respectively. He was working for IBM during 2 years, being involved in several international projects. Currently, he is Associate Professor in the Department of Electrical Engineering of the mentioned University, where he develops his docent and research work. He has been invited professor in Helsinki University of Technology (Finland) in 2005 and 2007, Michigan State University (USA) in 2010 and Korea University (Korea) in 2014. He has over 100 publications between international journals, conferences and books.

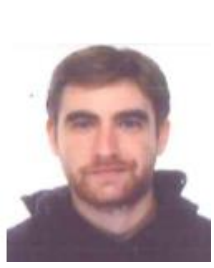

Raul Garcia-Hernandez received the B.S. degree in Industrial Engineering from the Universitat Politècnica de València, Spain, in 2014, and he is currently pursuing his Master degree in Industrial Engineering at the same University.

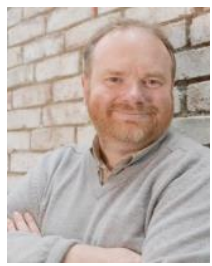

Malcolm D McCulloch. In 1993 Malcolm moved to Oxford University and to start up the Electrical Power Group (EPG), where is an Associate Professor. The group's focus is to develop and commercialize sustainable energy technologies in the four sectors of energy for development, domestic energy use, transport and renewable generation. His work addresses transforming existing power networks, designing new power networks for the developing world, developing new technology for electric vehicles and developing approaches to integrated mobility. He has over 100 Journal and refereed conference papers, 15 patents and 4 spinout companies.

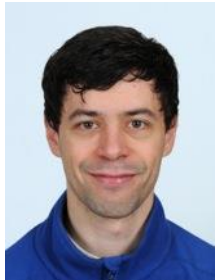

David A. Howey (M'10) received the B.A and M.Eng. degrees from Cambridge University, Cambridge, U.K., in 2002 and the Ph.D. degree from Imperial College London, London, U.K., in 2010. He is currently an Associate Professor in the Energy and Power Group, Department of Engineering Science, University of Oxford, Oxford, U.K. He leads projects on fast electrochemical modeling, modelbased battery management systems, battery thermal management, and motor degradation. His research interest include condition monitoring and management of electric and hybrid vehicle components.

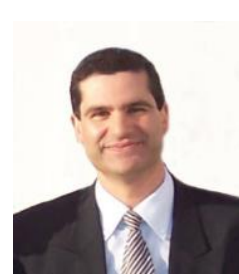

A. J. Marques Cardoso (S'89-A'95-SM'99) was born in Coimbra, Portugal, in 1962 . He received the E. E. diploma, the Dr. Eng. Degree and the Habilitation Degree, all from the University of Coimbra, Coimbra, Portugal, in 1985, 1995 and 2008, respectively. From 1985 till 2011, he was with the University of Coimbra, where he was Director of the Electrical Machines Laboratory. Since 2011, he has been with the University of Beira Interior (UBI), where he is a Full Professor at the Department of Electromechanical Engineering and Director of CISE - Electromechatronic Systems Research Centre (http://www.cise.ubi.pt). From September 2013 to January 2014 he was Vice-Rector of UBI. His teaching interests cover electrical rotating machines, transformers, and maintenance of electromechatronic systems, and his research interests are focused on condition monitoring and diagnostics of electrical machines and drives. He 
is the author of a book entitled Fault Diagnosis in Three-Phase Induction Motors (Coimbra Editora, Coimbra, 1991) and about 350 papers published in technical journals and conference proceedings. 